\title{
Systemic lupus erythematosus-a good maternal and fetal outcome
}

\author{
Preeti Lewis, Ashrulina Pal*
}

Department of Obstetrics and Gynecology, Grant Government Medical College and Sir J.J. Group of Hospitals, Mumbai, Maharashtra, India

Received: 26 September 2020

Accepted: 06 November 2020

\section{*Correspondence:}

Dr. Ashrulina Pal,

E-mail: pal2005ashru@gmail.com

Copyright: () the author(s), publisher and licensee Medip Academy. This is an open-access article distributed under the terms of the Creative Commons Attribution Non-Commercial License, which permits unrestricted non-commercial use, distribution, and reproduction in any medium, provided the original work is properly cited.

\begin{abstract}
Systemic lupus erythematosus (SLE) is a multisystemic autoimmune disease which primarily affects women in their reproductive years. The fertility is generally unaffected except in women with active disease, significant impairment of renal function, or high dose corticosteroid or cyclophosphamide therapy, which can result in ovarian dysfunction. This case report elaborates on the course of the pregnancy and the favourable maternal and fetal obstetric outcome of a 28-year-old female with known case of hypothyroidism who presented with chief complaints of generalised swelling all over the body and exertional dyspnoea and was later diagnosed to be a case of focal proliferative lupus nephritis, class III (ISN/RPS) on renal biopsy done postpartum. The effect of pregnancy on maternal disease is controversial. While some studies report exacerbation of SLE during pregnancy, others have not reported increased flares. The only study on this aspect of SLE from our country did not report a flare-up of disease during pregnancy.
\end{abstract}

Keywords: SLE, Hypothyroidism, Cyclophosphamide, Focal proliferative lupus nephritis, Class III (ISN/RPS)

\section{INTRODUCTION}

SLE is a multisystemic autoimmune disease which primarily affects women in their reproductive years. The fertility is generally unaffected except in women with active disease, significant impairment of renal function, or high dose corticosteroid or cyclophosphamide therapy, which can result in ovarian dysfunction.

\section{Effect of pregnancy on SLE}

The effect of pregnancy on maternal disease is controversial. While some studies report exacerbation of SLE during pregnancy.,2 Cyclophosphamide is contraindicated in pregnancy. Prophylactic corticosteroids to prevent lupus flares during pregnancy are not recommended. ${ }^{3}$

\section{Effect of SLE on pregnancy}

\section{Fertility}

In general, SLE does not affect the fertility of patients. Pregnancy rates of 0-4 pregnancies per patient have been described. ${ }^{4}$ The fertility may be adversely affected in a small subset of patients with renal failure, cyclophosphamide treatment, and anovulatory cycles due to active disease or high dose corticosteroids.

When and how-to time pregnancy

Planned pregnancies are a better option in lupus patients. Pregnancy should be undertaken at a time when the disease has been in remission for at least 6 months. 


\section{Obstetric issues during pregnancy}

Lupus patients have an increased risk of pre-eclampsia (3-5\%) as compared to women without SLE. ${ }^{7}$ Risk factor for pre-eclampsia include pre-existing hypertension, nephritis and presence of antiphospholipid antibodies (aPL). However, the treatment principles for preeclampsia and eclampsia are the same as in the non-lupus patient.

\section{Foetal issues}

The foetal outcome in lupus pregnancy is complicated by a higher rate of abortions (6-35\%), still-births, prematurity and intra-uterine growth retardation (IUGR).

Here we are discussing a good feto-maternal outcome in an active case of lupus nephritis grade III.

\section{CASE REPORT}

A 28-year-old female, married for 7 years, G2P1L1 with BD 31.5 weeks BS 30 weeks with known case of hypothyroidism for 6 years on tab thyroxine $200 \mathrm{mcg}$, presented with chief complaints of generalised swelling all over the body and exertional dyspnoea.

On examination, pallor present, generalised oedema ++ . Bilateral crepts on auscultation. On per abdomen examination, uterus size corresponded to 30 weeks of gestational age. Chest $\mathrm{X}$ ray revealed cardiomegaly, ECG showed low voltage complexes, USG Obstetrics suggestive of single live intra-uterine gestation of 31.4 weeks with normal doppler. $2 \mathrm{D}$ echo suggestive of moderate pericardial effusion with ejection fraction of $60 \%$ with healed tricuspid vegetations with tricuspid valve vegetations? infective endocarditis. Pericardial tapping was done s/o pericardial fluid ADA of $4.70 \mathrm{U} / \mathrm{L}$. Complete hemogram was done suggestive of anaemia and thrombocytopenia with $\mathrm{TSH}=18.57$, deranged RFTs (urea $=57$, creatinine $=1.6$ ) and normal LFT. 24 hours urine protein was $9.6 \mathrm{gm}$. Initially Blood culture revealed no growth. Later blood culture was found to be positive for Klebsiella pneumonia. Drug sensitivity test revealed resistance to cephalosporins, beta lactams and beta lactamase inhibitors and penicillin group. Anti TPO antibody titres-raised (249.3). Urine culture suggestive of Enterococcus faecalis and Candida species. Bilateral lower limb doppler revealed diffuse subcutaneous oedema. Pericardial fluid examination showed proteins $2.10 \mathrm{~g} / 100 \mathrm{cc}, \mathrm{RBC}=1600$. Urine routine microscopy revealed albumin $=0.3 \%$, strongly positive for blood, $\mathrm{RBCs}=100-150 / \mathrm{hpf}$, pus cells $=10-15 / \mathrm{hpf}$, occasional fine granular casts, few squamous cells and few gramnegative bacilli. ANA- $\mathrm{Ku}$ weak positive, ds DNA weakly positive, nucleosome positive, histones weakly positive, APLA IgG, IgM-positive. ANA-weakly positive of homogeneous pattern, titre 1:100. Procalcitonin-2.2 $\mathrm{ng} / \mathrm{ml}$. Complement levels: $\mathrm{C} 3=12.50 \mathrm{mg} / \mathrm{dl}, \mathrm{C} 4=1.81$ $\mathrm{mg} / \mathrm{dl}$. Left renal biopsy showed minimum hematoma.
Nephrologist and rheumatologist opinion taken and was advised Injection methylprednisolone and albumin was given for 5 days and started on intravenous heparin and oral prednisolone. Also, termination of pregnancy was advised as she had to be started on cyclophosphamide therapy. Hence induction of labour was done and she delivered a female baby of $1.4 \mathrm{~kg}$ birth weight vaginally and the baby was kept in neonatal intensive care unit (NICU) in view of low birth weight. After delivery renal biopsy was done which showed Focal proliferative lupus nephritis, class III (ISN/RPS). After ruling out active infective foci, she was given the $1^{\text {st }}$ cycle of cyclophosphamide. She was closely monitored daily. Review 2D echo revealed mobile tricuspid vegetation. Trans-esophageal echocardiography done suggestive of tricuspid vegetation of size $1.3 \times 1.4 \mathrm{~cm}$ ? Libman Sack's endocarditis and advised anticoagulation therapy and regular follow up 2D echo every 2 weeks. Pulmonary angiography revealed a normal study with mild cardiomegaly, mild pericardial effusion, minimal bilateral pleural effusion, mild ascites. Patient was then discharged on her day 38 postnatal period with normal RFT and LFT with baby being discharged at a weight of $2 \mathrm{~kg}$.

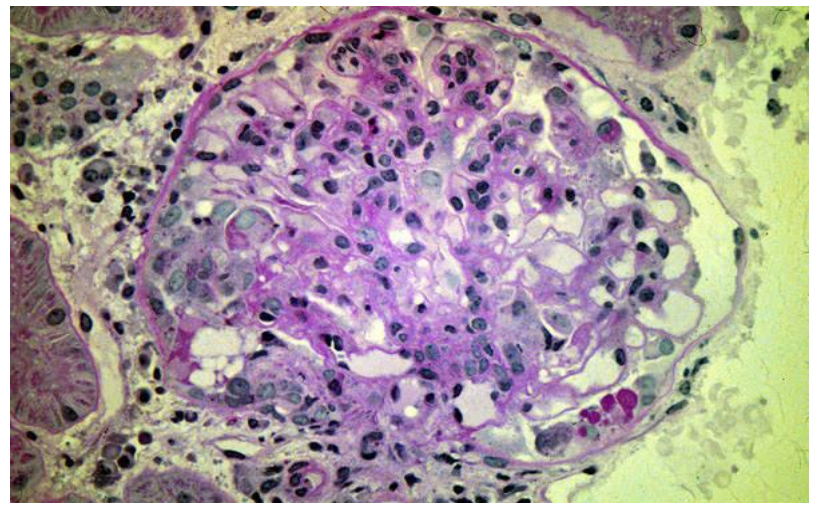

Figure 1: Microscopic representation of focal proliferative lupus nephritis, class III (ISN/RPS).

\section{DISCUSSION}

The effect of pregnancy on maternal disease is controversial. While some studies report exacerbation of SLE during pregnancy. ${ }^{1,2}$ Others have not reported increased flares. $^{3,5}$ The only study on this aspect of SLE from our country did not report a flare-up of disease during pregnancy. ${ }^{6}$ The clinician should be alive to the fact that assessment of lupus activity during pregnancy can be difficult. Physiological changes like alopecia, palmar erythema; increased glomerular filtration rate leading to increase in proteinuria etc. are liable to be misconstrued as flares of the disease by the unwary. ${ }^{7}$ Notwithstanding the varying reports available in literature, most rheumatologists agree that lupus flares are frequent in pregnancy with a flare rate of 0.06-0.136 per patient-month. Lupus may flare during any trimester or post-partum necessitating close follow up. The flares are generally mild with arthritis and cutaneous manifestations. ${ }^{4}$ Patients with pre-existing major organ 
involvement like kidneys need monitoring for renal flare. Flares are managed by escalation of treatment like nonsteroidal anti-inflammatory drugs (NSAIDs) and corticosteroids. Major organ flares (like renal disease) may need institution dose escalation of azathioprine.

In general, SLE does not affect the fertility of patients. So far as preservation of gonadal function is concerned intravenous pulse cyclophosphamide given intermittently is better than daily oral cyclophosphamide. The chances of permanent amenorrhea are higher with the latter. Two approaches have been suggested in an attempt to preserve fertility in lupus patients undergoing cyclophosphamide treatment ${ }^{8}$ : use of oral contraceptives to put the ovary to rest, and use of gonadotrophin releasing factor. Infertile women with lupus can be considered for invitro fertilization (IVF). Oestrogens given as part of IVF regimens may exacerbate SLE. However, most flares are manageable and the current consensus in not to deny this treatment option to selected patients. ${ }^{9}$

Patients need to be counselled about various contraceptive options. Barrier contraception (condom, diaphragm etc.) is the safest contraceptive method in SLE. ${ }^{8}$ Intra-uterine devices like copper-T which carry an increased risk of infection, especially in women on immunosuppressives, are best avoided. The currently available oral pills with very low dose of oestrogens are probably safe in SLE patients with one exception, namely patients with antiphospholipid syndrome. Most authorities believe that reports of SLE exacerbation with oral pills in the older literature were due to higher dose of oestrogens used. A large trial, safety of estrogens in lupus erythematosus: national assessment (SELENA), is currently underway in United States to address these issues. Progesterone only pills or depot progestogens are safe in lupus although side effects like menstrual irregularities, spotting, weight gain may adversely affect patient acceptance. Women who have completed their families can safely undergo tubal ligation.

The predictive factors for foetal wastage include active lupus nephritis, previous history of foetal death and the presence of aPL. ${ }^{10}$ Maternal hypertension and high dose steroids are predictors for prematurity and IUGR. High dose corticosteroids can also lead to premature rupture of membranes. Foetal loss related to the antiphospholipid syndrome usually occurs in the second and third trimesters. Both lupus anticoagulant and anti-cardiolipin antibodies (aCL) are associated with foetal loss. Corticosteroids are currently not advocated for the pregnancy losses due to APS unless there are associated autoimmune problems.

\section{CONCLUSION}

This case report of a multigravida showed good maternal and fetal outcome in a case of focal proliferative lupus nephritis class III.

\section{Funding: No funding sources \\ Conflict of interest: None declared \\ Ethical approval: Not required}

\section{REFERENCES}

1. Lockshin MD, Reinitz E, Druzin ML, Murrman M, Estes D. Lupus pregnancy: case-control prospective study demonstrating absence of lupus exacerbation during or after pregnancy. Am J Med. 1984;77(5):893-8.

2. Urowitz MB, Gladman DD, Farewell VT, Farewell VT, Stewart J, McDonald J. Lupus and pregnancy studies. Arthritis Rheum. 1993;36(10):1392-7.

3. Ruiz-Irastorza G, Lima F, Alves J, Simpson J, Hughes GR, Buchanan NM. Increased rate of lupus flare during pregnancy and the puerperium: a prospective study of pregnancies. Br J Rheumatol. 1996;35(2):133-8.

4. Mok CC, Wong RWS. Pregnancy in systemiclupus erythematosus. Postgrad Med J. 2001;77:157-65.

5. Petri M, Howard D, Repke J. Frequency of lupus flarein pregnancy. The Hopkins Lupus Pregnancy Center experience. Arthritis Rheum. 1991;34:153845.

6. Aggarwal N, Sawhney H, Vashishta K, Chopra S. Bambery Pregnancyin patients with systemic lupus erythematosus. Aust NZ J Obstet Gynaecol. 1999;39:28-30.

7. Buyon JP, Kalunian KC, Ramsey-Goldman R, Petri MA, Lockskin MD, Ruiz-Irastorza G et al. Assessing disease activity in SLE patients during pregnancy. Lupus. 1999;8:677-84.

8. Petri M. Systemic lupus erythematosus: Women's health issues. Bull Rheum Dis. 2000;49:1-3.

9. Guballa N, Sammaritano L, Schwartzmann S, Buyon J, Lockshin MD. Ovulation Induction and in vitro fertilizationin systemic lupus erythematosus and antiphospholipid syndrome. Arthritis Rheum. 2000;43:550-6.

10. Martinez-Rueda JO, Arce-Stalinas CA, Kraus A, Alcocer-Varela J, Alarcón-Segovia D. Factors associated with fetal losses in severe systemic lupus erythematosus. Lupus. 1996;5:113-9.

Cite this article as: Lewis $\mathrm{P}$, Pal A. Systemic lupus erythematosus-a good maternal and fetal outcome. Int J Reprod Contracept Obstet Gynecol 2020;9:5176-8. 